\title{
CAMA
}

Centre for Applied Macroeconomic Analysis

\section{Skill Composition, Fertility and Economic Growth}

\section{CAMA Working Paper 47/2013 August 2013}

\section{Creina Day}

Crawford School of Public Policy, ANU and

Centre for Applied Macroeconomic Analysis (CAMA), ANU

\begin{abstract}
While high fertility persists in the poorest countries and fertility declines with per capita income in developing countries, fertility and per capita income are now positively associated across most developed countries. This paper presents a model where a Ushaped relationship between overall fertility and per capita income reflects within country differences in workforce skill composition and household choice of occupation, fertility and childrearing. The fraction of skilled workers rises with economic growth. By allowing for both differences in the fertility of skilled and unskilled workers and purchased childrearing inputs, we explain a poverty trap with high fertility, fertility decline with economic development and the possible reversal of fertility decline in a developed economy where most workers are skilled.
\end{abstract}




\section{Keywords}

fertility; economic growth; education; childrearing

\section{JEL Classification}

J13; J24; O40

\section{Address for correspondence:}

(E) cama.admin@anu.edu.au

The Centre for Applied Macroeconomic Analysis in the Crawford School of Public Policy has been established to build strong links between professional macroeconomists. It provides a forum for quality macroeconomic research and discussion of policy issues between academia, government and the private sector.

The Crawford School of Public Policy is the Australian National University's public policy school, serving and influencing Australia, Asia and the Pacific through advanced policy research, graduate and executive education, and policy impact. 


\title{
SKILL COMPOSITION, FERTILITY AND ECONOMIC GROWTH
}

\author{
By CReina DaY* \\ Australian National University
}

\begin{abstract}
While high fertility persists in the poorest countries and fertility declines with per capita income in developing countries, fertility and per capita income are now positively associated across most developed countries. This paper presents a model where a U-shaped relationship between overall fertility and per capita income reflects within country differences in workforce skill composition and household choice of occupation, fertility and childrearing. The fraction of skilled workers rises with economic growth. By allowing for both differences in the fertility of skilled and unskilled workers and purchased childrearing inputs, we explain a poverty trap with high fertility, fertility decline with economic development and the possible reversal of fertility decline in a developed economy where most workers are skilled.
\end{abstract}

JEL codes: J13; J24; 040

Keywords: fertility; economic growth; education; childrearing

${ }^{*}$ Correspondence to: Creina Day, Fellow, Arndt Corden Department of Economics, Crawford School of Public Policy, Building 9, Australian National University, Canberra ACT 0200, Australia (creina.day@anu.edu.au). 


\section{INTRODUCTION}

This paper presents a comprehensive model that provides a consistent and cohesive explanation of high fertility in impoverished countries, fertility decline in developing countries and the recent reversal of fertility decline in most developed countries. The explanation for U-shaped fertility dynamics lies in the combined effects of the differential fertility of high and low skilled workers and the cost of rearing children using both parental time and purchased goods and services.

Emerging evidence suggests a fundamental change in the relationship between fertility and economic development. On the basis of cross-sectional and longitudinal data covering more than 100 countries, Myrskyla et al (2009) find that the well established negative relationship between fertility and development becomes positive at advanced stages of development. As countries progress to Human Development Index (HDI) levels exceeding $0.9^{1}$, the HDI-fertility association reverses to a positive relationship.

The HDI does not reveal information on how its components of per capita Gross Domestic Product (GDP), education and longevity interrelate or how within country differences in its dimensions ${ }^{2}$ may influence a country's overall fertility rate and level of economic development. The objective of this paper is to re-examine the theoretical relationship between overall fertility, within country differences in workforce skill composition and per capita GDP in light of recent evidence. Specifically, we provide a model-based hypothesis for fertility rebound at advanced stages of development.

The cross-country association between the total fertility rate $(\mathrm{TFR})^{3}$ and per capita GDP, measured at purchasing power parity (PPP) in constant 2005 US $\$$, in 1980-1984 and 2005-2009, is shown in Figures 1 and 2, respectively. Consistent with the United Nations (2011), three regions are defined based on levels of development. Whereas Figure 1 depicts the once strictly negative association between per capita GDP and fertility across all countries, Figure 2 reveals a distinction in the fertilityper capita GDP association across the three regions. Three observations on the cross-country association are reviewed in light of within country skill composition of the workforce.

Firstly, fertility remains high and the average skill level of the workforce ${ }^{4}$ remains low in the poorest sub-Saharan African countries. In Ethiopia, the TFR remains

\footnotetext{
${ }^{1}$ The HDI is an index, primarily used by the United Nations to evaluate development, which combines with equal weight indicators of a country's health conditions, standard of living and human capital. For most developed countries, HDI levels exceed 0.9 , which corresponds to 75 years life expectancy, per capita Gross Domestic Product (GDP) US\$25,000 in year 2000 PPP and a 0.95 human capital index (based on literacy and enrolment rates).

${ }^{2}$ Grimm et al (2008) find large discrepancies in the dimensions of HDI within countries.

${ }^{3}$ The total fertility rate indicates the average births per woman in her lifetime if she were to experience the current age-specific fertility rates throughout her lifetime. As a cross-sectional measure, the TFR may rise due not only to a rise in completed fertility (quantum effects) but also to the end of birth postponement (tempo effects). Goldstein et al (2009) and Luci and Thevenon (2011) find that tempo-adjusted fertility rates have risen with per capita GDP in more developed countries, suggesting increases in quantum, analysed in this paper, have accompanied TFR recovery at advanced stages of development.

${ }^{4}$ Data on fraction of workers in non-agricultural employment and average years of schooling of the workforce are sourced from World Bank (2012) and Morrison and Murtin (2009), respectively.
} 
above 5 children per woman, more than 80 per cent of total employment remains in agriculture and workers have on average two years of schooling, which is half the educational attainment of the United Kingdom in 1870.

Secondly, fertility declines and per capita GDP rises in less developed countries as average years of schooling rise and the occupational structure shifts to nonagricultural employment. The experience of China and Thailand, where average years of schooling have doubled to 8.5 years between 1980 and 2009 and the TFR has fallen to around 1.6 births per woman, typifies this demographic transition.

Finally, the once negative cross-country association between fertility and per capita GDP has become positive for more developed countries. ${ }^{5}$ This observation is consistent with Luci and Thevenon (2011), who confirm a positive impact of per capita GDP on fertility for high income OECD countries, after controlling for birth postponement and country-specific effects. More than an emerging positive association, Figure 2 shows a divide between more developed countries, all with maximum average years of schooling and high levels of per capita GDP, but with either high or low fertility. The opportunity for parents to reconcile work and child rearing is a key factor determining on which side of the positive trend line in Figure 2 a country falls (Thevenon, 2011). This is a theme which this paper develops by allowing for purchased child rearing inputs.

Existing models of endogenous fertility predict a negative relationship between per capita GDP and fertility. Economic growth induces fertility decline by increasing either: female relative wages and the opportunity cost of maternal time (Barro and Becker, 1988; Galor and Weil, 1996); the relative return to investing in education per child (Becker et al, 1990, de la Croix and Doepke, 2003) or employment opportunities for women (Rees and Reizman, 2012), whereby parents face a child quality-quantity trade-off; or the fraction of skilled workers, who have fewer children than their unskilled counterparts (Kimura and Yasui, 2007; Chen, 2010).

Whereas in the majority of theoretical studies, parents decide on the educational investment in their children, in this paper, we allow parents to invest in their own education, which determines whether they will become high skilled or low skilled workers. This approach enables us to analyze three distinct effects of per capita GDP on total fertility, at different stages of development, through within country differences in the skill composition of the workforce. ${ }^{6}$ Kimura and Yasui (2007) and Chen (2010) focus on the role of changes in the skill composition of the workforce to explain a negative relationship between overall fertility and economic development. Parental time spent rearing children is fixed in these models. This assumption is a shortcoming when analyzing the behavior in overall fertility because it implies wages do not affect household fertility. However, we find their approach of analyzing fertility over two phases, distinguished by the skill composition of the workforce to be a useful starting point for the analysis of this paper, which focuses on explaining the emergence of a positive relationship between overall fertility and per capita income at advanced stages of development.

This paper contributes to the literature by providing a mechanism whereby fur-

\footnotetext{
${ }^{5}$ For 2005-2009, the correlation between fertility and per capita GDP is positive and significant across more developed countries. The correlation coefficient is 0.58 with a p-value of 0.003 .

${ }^{6}$ The focus in this paper on within country household inequality does not deny the influence of other factors such as within household gender inequality. Extending our model along these lines is an interesting direction for future research.
} 
ther economic growth in more developed regions reverses fertility decline. We extend Kimura and Yasui (2007) by incorporating a more general form of child rearing costs. In this paper, children are reared by combining parental time and purchased goods and services, so that households decide on both the number of children and child rearing inputs.

Households differ in that better educated parents have fewer children than their low skilled counterparts. This is consistent with international evidence from both long run historical data (for a review, see Sato et al (2008)) and micro data (Rosenzweig, 1990; Beenstock, 2007). At low levels of development, an economy may experience persistent high fertility and a low skilled workforce or fertility decline as economic growth raises the fraction of skilled workers. At advanced stages of development, skilled workers find children more affordable, but more costly to rear using parental time as their wages rise. ${ }^{7}$ We might reasonably expect highly educated parents to choose more children if purchased inputs mitigate the rising opportunity cost of parental time. There is some evidence that this has indeed occurred in some developed economies. For instance, in the United States, child rearing is a relatively goods intensive activity (Gronau and Hamermesh, 2006).

Section 2 provides a theoretical model capable of analyzing the interrelationship between workforce skill composition, overall fertility and per capita GDP for least developed, developing and developed countries. Section 3 analyses the U-shaped interrelationship between fertility and economic growth. Section 4 concludes.

\section{Model}

Consider an overlapping generations model in which people live for three periods. In childhood, an agent consumes time, as well as goods and services, from their parents. In adulthood, an agent supplies labor, raises children, and may receive further education. The agent decides whether or not to undertake training to become a skilled worker, how many children to have and the inputs with which to rear them. In old age, an agent is retired from the labor force and consumes the proceeds of their savings from the previous period.

The closed economy identity of savings and investment provides the link with growth in the capital stock, skill composition of the workforce and wages, which in turn influence fertility. Rising skilled intensity is a consequence of economic growth. Skilled labor is complementary to physical capital. Combined with the neoclassical capital intensity effect, this final feature generates a feedback loop between growth in output per worker and fertility.

We model the economy as it moves through two phases, distinguished by the skill composition of the labor force. We set out to explore the behavior of fertility, and its implications for growth, during an initial phase when the labor force comprises skilled and unskilled workers, before entering a second phase when every agent chooses to become skilled.

\subsection{Production of Final Output}

Physical capital $(K)$, unskilled labor $\left(L_{t}^{u}\right)$ and skilled labor $\left(L_{t}^{s}\right)$ are factors of production, all with non-increasing marginal products. The greater the capital-labor

\footnotetext{
${ }^{7}$ Cette et al (2007) find evidence corroborating these simultaneous and opposing fertility effects.
} 
ratio in the economy, the more highly rewarded is skilled labor relative to unskilled labor. This is consistent with the relative rise in rewards to skilled labor characterizing economic growth.

The production function is given by

$$
Y_{t}=A\left[K_{t}^{\alpha}\left(L_{t}^{s}\right)^{(1-\alpha)}+b L_{t}^{u}\right] ; \quad A>0 ; \quad b>0 ; \quad \alpha \in(0,1)
$$

where the separability captures the assumption that, whereas capital complements skilled labor, unskilled labor is a perfect substitute for other factors of production. ${ }^{8}$

Each household (agent) is endowed with a unit of time, which can be allocated to child rearing, labor force participation and education (training). Each agent chooses whether to become a skilled worker or an unskilled worker. To supply skilled labor, an agent must spend a fraction of their time endowment, $\tau \in(0,1)$, to acquire skill.

Each household chooses the number of children, where $n_{t}^{s}$ and $n_{t}^{u}$ denote the pairs of children of skilled and unskilled agents, respectively. To raise a pair of children, an agent purchases goods and services and employs a fraction of their time endowment, denoted $\hat{x}$ and $\hat{z}$, respectively, where $\hat{z} \in(0,1)$.

Let $N_{t}$ be the number of working age agents and $\varphi$ be the ratio of skilled workers to all workers. The aggregate supply of skilled labor and unskilled labor at time $t$ is $L_{t}^{s}=\left(1-\tau-\hat{z} n_{t}^{s}\right) \varphi N_{t}$ and $L_{t}^{u}=\left(1-\hat{z} n_{t}^{u}\right)(1-\varphi) N_{t}$, respectively.

Perfectly competitive factor markets imply

$$
\begin{aligned}
w_{t}^{s} & =\partial Y_{t} / \partial L_{t}^{s}=A(1-\alpha)\left[k_{t} / h_{t} \varphi\right]^{\alpha} \\
w_{t}^{u} & =A b \\
R_{t+1} & \equiv\left(1+r_{t+1}\right)=\partial Y_{t} / \partial K_{t}=A \alpha\left[k_{t} / h_{t} \varphi\right]^{\alpha}
\end{aligned}
$$

where $k_{t} \equiv K_{t} / N_{t}$ and $h_{t} \equiv L_{t}^{s} / \varphi N_{t}$ denote physical capital per working age agent and skilled labor per skilled working age agent, respectively. Ceteris paribus, an increase in capital intensity will therefore raise the wage ${ }^{9}$ for skilled labor $\left(w_{t}^{s}\right)$ while the wage for unskilled labor $\left(w_{t}^{u}\right)$ is constant.

\subsection{Household optimization}

Each agent (household) derives utility directly from the number of children. Skilled and unskilled agents are assumed to have the same preferences. The household utility function is

$$
u_{t}=\gamma \ln \left(n_{t}\right)+\lambda \ln \left(c_{t}\right)+\delta \ln \left(c_{t+1}\right) ; \gamma+\lambda+\delta=1
$$

where $c_{t}, c_{t+1}$ and $n_{t}$ denote working-age consumption, old-age consumption and pairs of children, respectively, chosen by the household at time $t ; \gamma \in(0,1)$ and $\lambda \in$ $(0,1)$ capture the relative weights given to children and working-age consumption and $\delta \in(0,1)$ is the discount factor.

Taking the lead of Balestrino et al (2003) and Apps and Rees (2004), we assume that $n_{t}$ pairs of children are reared at home by combining parental time and

\footnotetext{
${ }^{8}$ This functional form is common to endogenous fertility models with wage differentials (Galor and Weil, 1996; Kimura and Yasui, 2007; Chen, 2010).

${ }^{9}$ This is the real wage, with the price of the aggregate good normalized to 1.
} 
goods and services purchased from the market, both of which are essential. The "production function" for child rearing is a Cobb-Douglas specification

$$
n_{t}=\left(z_{t}\right)^{a}\left(x_{t}\right)^{1-a} ; a \in(0,1)
$$

where $x$ and $z$ denote total child rearing goods and services and total time input, respectively.

The total cost of rearing children for agent $i$ is

$$
C_{t}^{i}=w_{t}^{i} z_{t}^{i}+p_{x}(1-\beta) x_{t}^{i} ; \beta \in(0,1)
$$

where $p_{x}$ and $\beta$ denote the price and government subsidy per unit of purchased goods and services, respectively. ${ }^{10}$

The household first chooses the input mix, for a given $n_{t}$, so as to minimize (7) subject to (6), yielding child rearing input demands for time and goods

$$
\begin{aligned}
z_{t}^{i} & \equiv \hat{z}\left(w_{t}^{i}, \beta\right) n_{t}^{i}=\left[\frac{p_{x}(1-\beta) a}{w_{t}^{i}(1-a)}\right]^{1-a} n_{t}^{i} \\
x_{t}^{i} & \equiv \hat{x}\left(w_{t}^{i}, \beta\right) n_{t}^{i}=\left[\frac{w^{i}(1-a)}{p_{x}(1-\beta) a}\right]^{a} n_{t}^{i}
\end{aligned}
$$

and the implicit cost per unit

$$
p\left(w_{t}^{i}, p_{x}, \beta\right)=\left[w^{i}\right]^{a}\left[p_{x}(1-\beta)\right]^{1-a} B
$$

where $B=a^{-a}(1-a)^{-(1-a)}, \hat{z}_{t}^{i}=\partial p(.) / \partial w_{t}^{i}$ and $\hat{x}_{t}^{i}=\partial p(.) / \partial p_{x}(1-\beta)$.

Each agent faces the second period budget constraint

$$
c_{t+1}=s_{t}\left(1+r_{t+1}\right)\left(1-T_{t+1}\right)
$$

where $r_{t+1}$ denotes the rate of return on savings, $s_{t}, T_{t+1}$ denotes the rate of taxation on old age consumption. ${ }^{11}$

A skilled worker faces the first period budget constraint

$$
p\left(w_{t}^{s}, p_{x}, \beta\right) n_{t}+s_{t} \leq w_{t}^{s}(1-\tau) .
$$

Maximizing (5) with respect to (10) and (11), it follows that the number of children and the savings of a skilled worker are

$$
\begin{aligned}
n_{t}^{s} & =\frac{\gamma(1-\tau)}{B}\left[\frac{w_{t}^{s}}{p_{x}(1-\beta)}\right]^{1-a} \\
c_{t}^{s} & =\lambda(1-\tau) w_{t}^{s} \\
s_{t}^{s} & =(1-\gamma-\lambda)(1-\tau) w_{t}^{s} .
\end{aligned}
$$

An unskilled worker faces the first period budget constraint

$$
p\left(w_{t}^{u}, \beta\right) n_{t}+s_{t} \leq w_{t}^{u}
$$

\footnotetext{
${ }^{10}$ As with $w_{t}^{s}, p_{x}$ is the real price of child-rearing goods and services. Subsidies are financed by a tax on old age consumption (see second period budget constraint below).

${ }^{11}$ Subsidies are financed by a tax on old age consumption so as to satisfy the balanced-budget constraint: $\beta_{t} \hat{x} n_{t}\left[n_{t-1} L_{t-1}\right]=s_{t-1}\left(1+r_{t}\right) T_{t} L_{t-1}$. Although endogenous at the aggregate level, the rate of subsidy and taxation is treated as exogenous by each individual household.
} 
Maximizing (5) with respect to (10) and (13), it follows that the number of children and the savings of an unskilled worker are

$$
\begin{aligned}
n_{t}^{u} & =\frac{\gamma}{B}\left[\frac{w_{t}^{u}}{p_{x}(1-\beta)}\right]^{1-a} \\
c_{t}^{u} & =\lambda w_{t}^{u} \\
s_{t}^{u} & =(1-\gamma-\lambda) w_{t}^{u} .
\end{aligned}
$$

Since agents choose to become skilled or to remain unskilled, agents are indifferent between becoming skilled and remaining unskilled in an equilibrium where both types of workers exist. Equating the indirect utility of both types of workers yields the arbitrage condition

$$
\frac{w_{t}^{u}}{w_{t}^{s}}=(1-\tau)^{1 /(1-a \gamma)}
$$

where the equilibrium wage rate of a skilled worker is higher than that of an unskilled worker, since $\tau \in(0,1) ; a \in(0,1)$ and $\gamma \in(0,1) .{ }^{12}$

Intuitively, each agent derives utility from children and old age consumption. A skilled worker has lower fertility than an unskilled worker. On the one hand, to become a skilled worker, an agent must spend a fraction of their time training, and therefore has less time to rear children. On the other hand, higher wages make children more affordable for a skilled worker. Consistent with evidence that fertility of skilled workers is less than fertility of unskilled workers (Rosenzweig, 1990; Beenstock, 2007) we assume that the former effect dominates and fertility of a skilled worker is less than fertility of an unskilled worker. Therefore, in order to be indifferent between becoming skilled or remaining unskilled, a skilled worker must earn a higher wage to fund higher old age consumption than their unskilled counterpart.

\subsection{Dynamic system}

The dynamics of the economy can be summarized through the law of motion for the capital stock per working age household. The market clearing condition implies that the capital stock at period $t+1$ is determined by the savings of working age households at the end of period $t$

$$
K_{t+1}=s_{t} N_{t}
$$

where the total savings rate at time $t$ is

$$
s_{t}=\left[\varphi_{t} s_{t}^{s}+\left(1-\varphi_{t}\right) s_{t}^{u}\right]
$$

The number of working age households at time $t+1$ is

$$
N_{t+1}=f_{t} N_{t}
$$

\footnotetext{
${ }^{12}$ Although (12a) and (14a) indicate individual fertility is increasing in wages relative to childcare prices, a positive wages effect does not occur until the second phase when every agent is skilled. (3) and (15) indicate $w_{t}^{s}$ and $w_{t}^{u}$ are constant throughout the initial phase where both skilled and unskilled workers exist. The average wage is increasing in $\varphi_{t}$, which we show herein rises with capital per worker. Consistent with the empirical finding, fertility initially decreases with increasing education and per capita income.
} 
where the total fertility rate at time $t$ is

$$
f_{t}=\varphi_{t} n_{t}^{s}+\left(1-\varphi_{t}\right) n_{t}^{u}
$$

Capital stock per household is therefore given by

$$
k_{t+1}=\frac{K_{t+1}}{N_{t+1}}=\frac{s_{t}}{f_{t}}
$$

From (18), an equation of motion $k_{t+1}=\phi\left(k_{t}\right)$ is obtained, since overall savings and fertility is determined by $\varphi_{t}$, which we will see is a function of $k_{t}$ during an initial phase, and savings and fertility of a skilled worker are determined by $w_{t}^{s}$, which in turn is a function of $k_{t}$ during the second phase.

It follows from (2), substituting for $\hat{z} n_{t}^{s}$, (3), and (15) that the fraction of skilled workers, $\varphi$, is a function of $k_{t}$, as implied by the following expression

$$
\varphi\left(k_{t}\right)=\frac{(1-\tau)^{\frac{1}{\alpha(1-a \gamma)}-1}}{(1-a \gamma)}\left(\frac{1-\alpha}{b}\right)^{1 / \alpha} k_{t} \equiv \theta k_{t}
$$

where $\varphi\left(k_{t}\right)$ has an upper bound of 1 . Once $k_{t}$ reaches a sufficiently high level, $\bar{k}$, all agents choose to become skilled.

Thus, the fraction of skilled workers is

$$
\varphi\left(k_{t}\right)=\left\{\begin{array}{cc}
1 & \text { if } k_{t} \geq \bar{k} \\
\theta k_{t} & \text { if } k_{t}<\bar{k}
\end{array}\right.
$$

where $\theta \equiv \frac{(1-\tau)^{\frac{1}{\alpha(1-a \gamma)}}-1}{(1-a \gamma)}\left(\frac{1-\alpha}{b}\right)^{1 / \alpha}$ and $\bar{k}=\theta^{-1}$, yielding the following

Proposition 1: The fraction of skilled workers is non decreasing in the capital stock per household, and strictly increasing in the capital stock per household for $k_{t}<\bar{k}$.

\section{EQUATION OF MOTION}

Substituting into (18) from (16) and (17), the equation of motion for the system is derived from

(21) $k_{t+1}=B \frac{(1-\gamma-\lambda)}{\gamma}\left\{\begin{array}{cl}\left(w_{t}^{s}\right)^{a}\left[p_{x}(1-\beta)\right]^{1-a} & \text { if } k_{t} \geq \bar{k} \\ \frac{\theta k_{t} w_{t}^{s}(1-\tau)+\left(1-\theta k_{t}\right) w_{t}^{u}}{\left[\theta k_{t}\left(\frac{w_{t}^{s}}{p_{x}(1-\beta)}\right)^{1-a}(1-\tau)+\left(1-\theta k_{t}\right)\left(\frac{w_{t}^{u}}{p_{x}(1-\beta)}\right)^{1-a}\right]} & \text { if } k_{t}<\bar{k}\end{array}\right.$

where

$$
w_{t}^{s}=A(1-\alpha) \begin{cases}{\left[k_{t} /(1-a \gamma)(1-\tau)\right]^{\alpha}} & \text { if } k_{t} \geq \bar{k} \\ {[(1-a \gamma)(1-\tau) \theta]^{-\alpha}} & \text { if } k_{t}<\bar{k}\end{cases}
$$


Referring to the Appendix, capital per household evolves over time from a historically given initial level according to

$$
\begin{aligned}
k_{t+1} & =\phi\left(k_{t}\right) \\
& =A^{a} \tilde{B} \frac{(1-\gamma-\lambda)}{\gamma}\left\{\begin{array}{cl}
{\left[\frac{(1-\alpha)}{(1-a \gamma)^{\alpha}(1-\tau)^{\alpha}}\right]^{a} k_{t}^{a \alpha}} & \text { if } k_{t} \geq \bar{k} \\
b^{a} \frac{1+\theta\left\{(1-\tau)^{\frac{-a \gamma}{(1-a \gamma)}}-1\right\} k_{t}}{1-\theta\left\{1-(1-\tau)^{\frac{a(1-\gamma)}{(1-\alpha \gamma)}}\right\} k_{t}} & \text { if } k_{t}<\bar{k}
\end{array}\right.
\end{aligned}
$$

where $\tilde{B}=a^{-a}(1-a)^{-(1-a)}\left(p_{x}(1-\beta)\right)^{1-a}$.

The following properties of the equation of motion (23) ensure existence of steady equilibrium(a)

$$
\phi(0)=(A b)^{a} \tilde{B} \frac{(1-\gamma)}{\gamma}>0 \text { and } \lim _{k_{t} \rightarrow \infty} \phi^{\prime}\left(k_{t}\right)=0 .
$$

Furthermore, the equation of motion has curvature properties which we summarize with the following

Proposition 2: $\quad \phi\left(k_{t}\right)$ is increasing and convex in $k_{t}$ over the interval $(0, \bar{k})$; increasing and concave over the interval $(\bar{k}, \infty)$.

Proof See Appendix. ${ }^{13}$

Result 1: If the initial state of technology is sufficiently low, the economy converges to a poverty trap, $k_{L}^{*}$, or high education steady state, $k_{H}^{*}$, depending on $k_{0 .}{ }^{14}$ The poverty trap is characterized by high fertility due to a high fraction of unskilled workers.

Referring to Figure 3, for a low initial $A$, initial capital per person determines whether an economy converges to a high education state or a poverty trap. If $k_{0}<\bar{k}$ such that $\phi\left(k_{0}\right)<k_{0}$, the economy converges to a poverty trap, where the low $k_{L}^{*}$ determines a high $\varphi_{L}^{*}$. The high fraction of unskilled workers implies high overall fertility, since unskilled workers have more children. For a sufficiently high $A$, there exists a unique steady state equilibrium, $k^{*}$, comprising skilled workers and a stationary fertility rate, $f^{*}$. We explore the behavior of fertility in convergence to this equilibrium, which describes a developed or high income economy.

Result 2: If the initial state of technology is sufficiently high, the economy converges to a high education steady state, $k^{*}$. In transition to this steady state, overall fertility decreases over the interval $(0, \bar{k})$ and increases over the interval $\left(\bar{k}, k^{*}\right)$. Skilled workers bring about the reversal of fertility decline.

\footnotetext{
${ }^{13}$ Intuitively, curvature properties follow from the dynamic behaviour of savings and fertility. For instance, when $k_{t} \geq \bar{k}$, fertility rises less than does savings, such that $\phi\left(k_{t}\right)$ follows the path of the per unit child rearing cost function, $p\left(w_{t}^{s}, p_{x}, \beta\right)$ which is increasing and concave in $k_{t}$.

${ }^{14}$ There is a third possibility, where $A$ is extremely low such that $\phi\left(k_{t}\right)$ intersects the $45^{0}$ line once at $k^{*}<k_{L}^{*}$. In this case, a poverty trap is the only possible equilibrium.
} 
Using (12a), (14a), (17), (19) and (22), the average fertility rate, $f_{t}$, is expressed as a function of $k_{t}$,

$$
f\left(k_{t}\right)=\left\{\begin{array}{cc}
\frac{\gamma}{B}\left[\frac{A b}{p_{x}(1-\beta)}\right]^{1-a}\left[1-\theta\left(1-(1-\tau)^{\frac{a(1-\gamma)}{(1-a \gamma)}}\right) k_{t}\right] & \text { if } k_{t}<\bar{k} \\
\frac{\gamma(1-\tau)^{1-\alpha(1-a)}}{B}\left[\frac{A(1-\alpha)}{p_{x}(1-\beta)(1-a \gamma)^{\alpha}}\right]^{1-a} k_{t}^{\alpha(1-a)} & \text { if } k_{t} \geq \bar{k}
\end{array}\right.
$$

where, referring to the appendix,

$$
\begin{array}{lll}
f^{\prime}\left(k_{t}\right)<0 & f^{\prime \prime}\left(k_{t}\right)=0 & \text { if } k_{t}<\bar{k} \\
f^{\prime}\left(k_{t}\right)>0 & f^{\prime \prime}\left(k_{t}\right)<0 & \text { if } k_{t} \geq \bar{k}
\end{array}
$$

and

$$
f(\bar{k})=\frac{\gamma}{B}\left[\frac{A b}{p_{x}(1-\beta)}\right]^{1-a}(1-\tau)^{\frac{a(1-\gamma)}{(1-a \gamma)}}
$$

where $\bar{k}=\left(\frac{b}{1-\alpha}\right)^{1 / \alpha}(1-a \gamma) /(1-\tau)^{\frac{1}{\alpha(1-a \gamma)}-1}$.

(25b) implies a negative relationship between fertility and capital per capita, and therefore income per capita, when the economy initially comprises skilled and unskilled workers. This relationship becomes positive once sufficient capital per capita, $\bar{k}$, has been accumulated such that all workers are skilled.

Based on (25a) - (25c), Figure 4 depicts the dynamics of the average fertility rate. When $k_{t}<\bar{k}$, the economy comprises skilled and unskilled workers. Since a skilled worker has less children than an unskilled worker, average fertility falls as the fraction of skilled workers rises with $k_{t}$. When $k_{t} \geq \bar{k}$, all workers are skilled and the negative composition effect on average fertility disappears. Capital complements skilled labor, raising the marginal product of skilled labor at a decreasing rate. As skilled wages rise, the opportunity cost of raising children increases, but so to does potential income. Substitution of purchased inputs for parental time mitigates some of the rising opportunity cost for skilled workers, so that the income effect dominates the substitution effect and a skilled worker chooses to have more children. Average fertility rises with $k_{t}$ until it converges to the stationary rate, $f\left(k^{*}\right)$.

(25c) provides the critical values for $\bar{k}$ and $f(\bar{k})$ for which a positive relationship between fertility and per capita income emerge. The level of $f(\bar{k})$ is higher, the lower the subsidized price of purchased child rearing inputs $\left(p_{x}(1-\beta)\right)$ at time $\bar{t}$, suggesting a role for government policy. For a sufficiently large $\tau, \bar{k}$ is increasing in $a$, the production share of time in child rearing. ${ }^{15}$ Ceteris paribus, developed countries where child rearing is inherently more (less) intensive in parental time reach the fertility rebound stage at a higher (lower) level of capital per capita. The value of $a$ affects not only the onset but also the scale of fertility rebound. Referring to the appendix, $f^{\prime}\left(k_{t}\right) \rightarrow 0$ as $a \rightarrow 1$. In the special case where the availability of purchased child rearing inputs is restricted $(a=1)$, fertility of skilled workers is no longer affected by wages growth. This may explain more prolonged periods of low fertility in some high income economies, such as Japan and Italy.

$$
{ }^{15} \frac{d \bar{k}}{d a}=-\frac{\gamma}{(1-a \gamma)}\left[1+\frac{\ln (1-\tau)}{\alpha(1-a \gamma)}\right] \bar{k}>0 \Leftrightarrow \ln (1-\tau)<-\alpha(1-a \gamma) .
$$




\section{Conclusions}

The once negative association between fertility and per capita income is no longer observed across all countries. Fertility remains high in impoverished countries where the majority of workers are unskilled, declines with rising per capita income in developing countries as the fraction of skilled workers rises and is now positively associated with per capita income across more developed countries where the workforce is predominantly skilled.

The model of economic growth and household choice of occupation, fertility and child rearing presented in this paper explains these observations. Within an economy, skilled workers have fewer children than low skilled workers. As an economy moves through two phases distinguished by the skill composition of the workforce, the analysis predicts that as an economy grows, overall fertility

- initially declines with rising skill intensity of the workforce; and

- then may recover with rising wages of a skilled workforce.

Some testable implications arise for future empirical research on fertility rebound at advanced stages of economic development. The results suggest that subsidies to purchased child rearing inputs raise fertility and that the production share of purchased inputs in child rearing positively affects the onset and scale of fertility rebound. This implies that future empirical work on fertility rebound consider cross country variation in the production weight and price of a child rearing alternative to parental time, which in turn depends on cultural factors and government policy. 


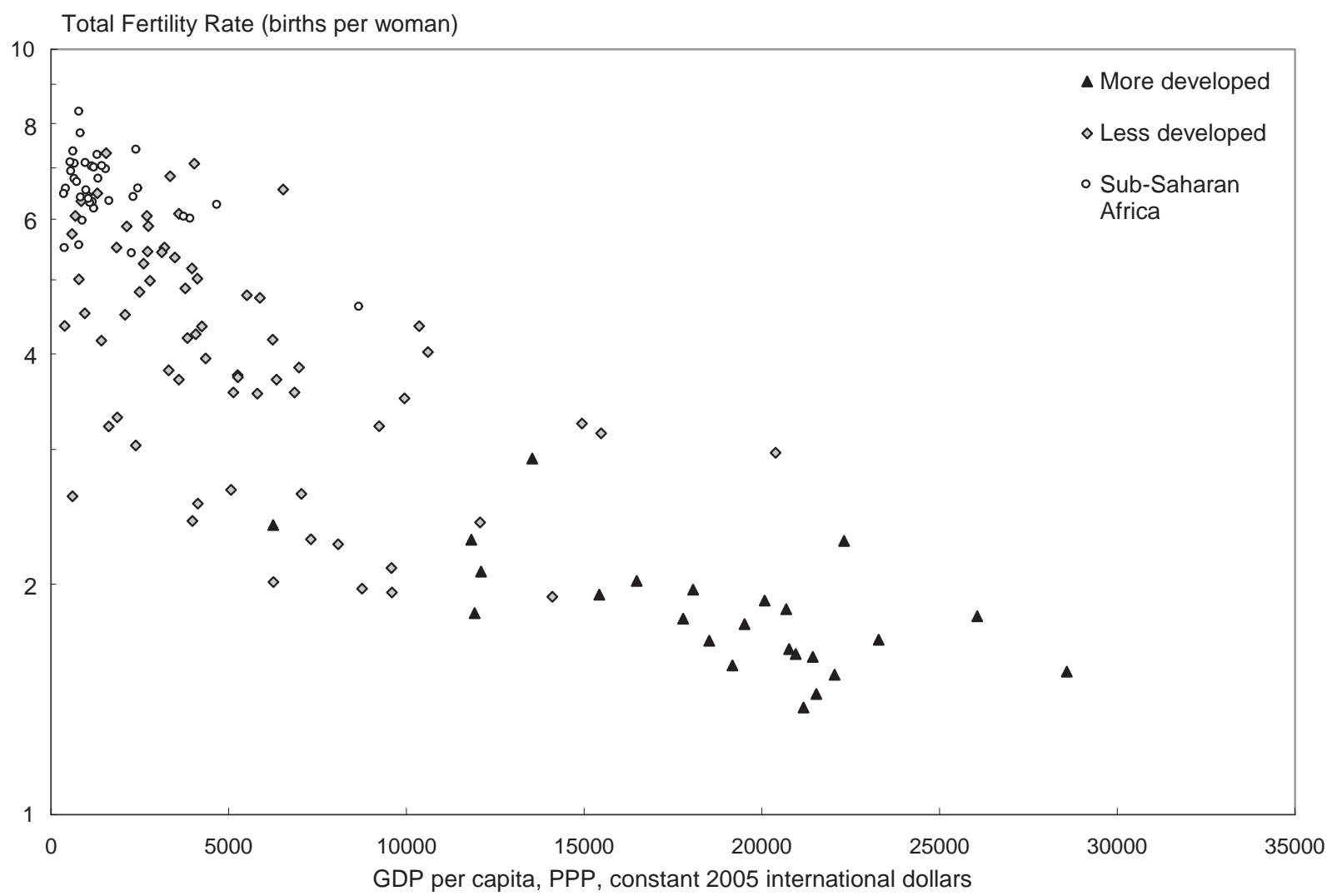

Figure 1. Fertility and Per Capita GDP in 130 Countries, 1980-1984 ${ }^{16}$

Source World Bank (2012)

\footnotetext{
${ }^{16}$ The sample of 130 countries, consistent across Figures 1 and 2, excludes major oil producing economies and Luxembourg, whose per capita GDP significantly outstrips other high income economies. Luxembourg's per capita GDP at PPP for $2005-2009$ is $\$ 70,911$, approximately two thirds higher than that of the United States.

More developed regions comprise all countries of Europe, Northern America, Australia, New Zealand and Japan. Less developed regions comprise countries of Africa (excluding sub-Saharan Africa), Asia (excluding Japan), Latin America and the Caribbean plus Melanesia, Micronesia and Polynesia. Sub-Saharan Africa comprises the least developed countries of Africa.
} 


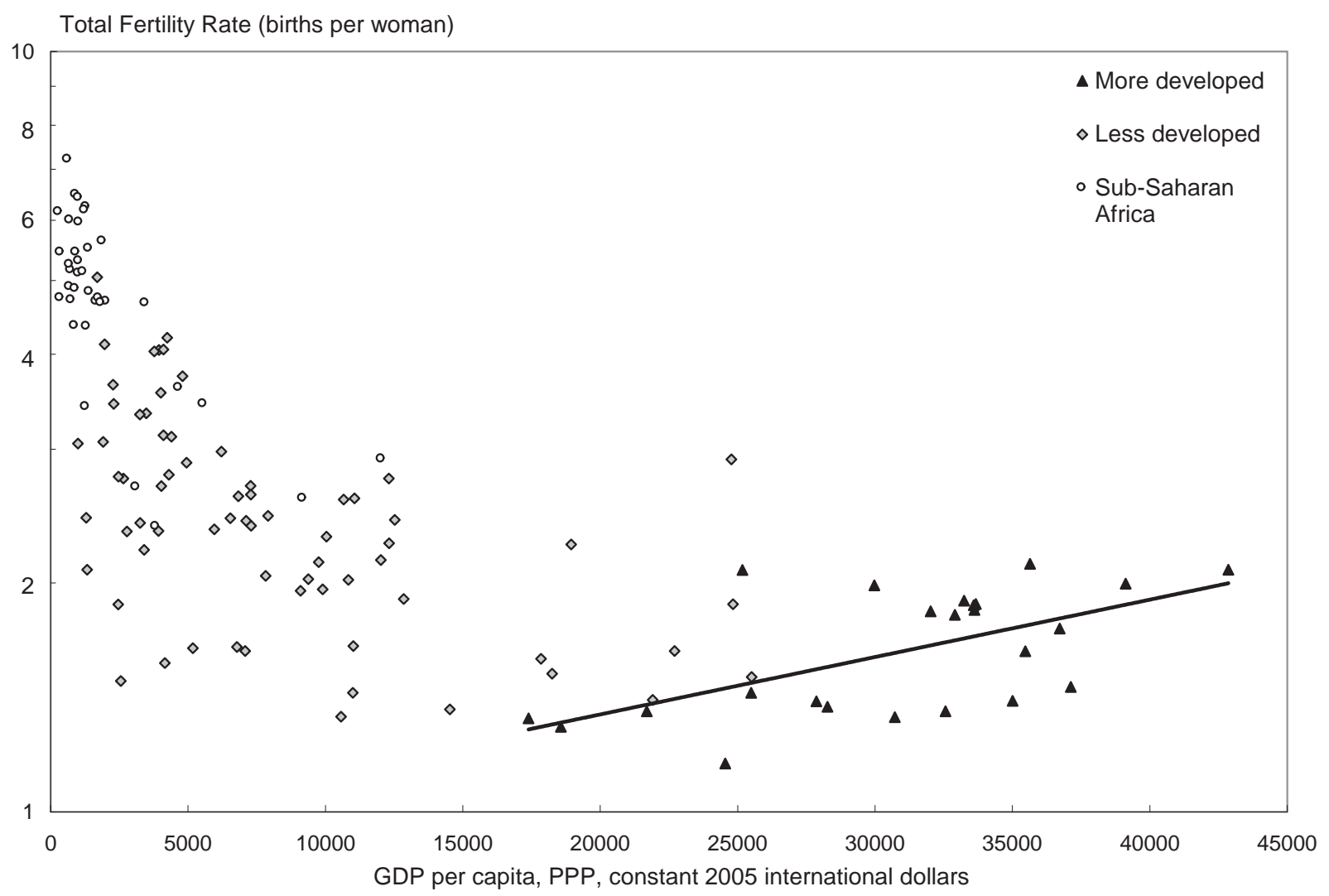

Figure 2. Fertility and Per Capita GDP in 130 Countries, 2005-2009 Source: World Bank (2012) 


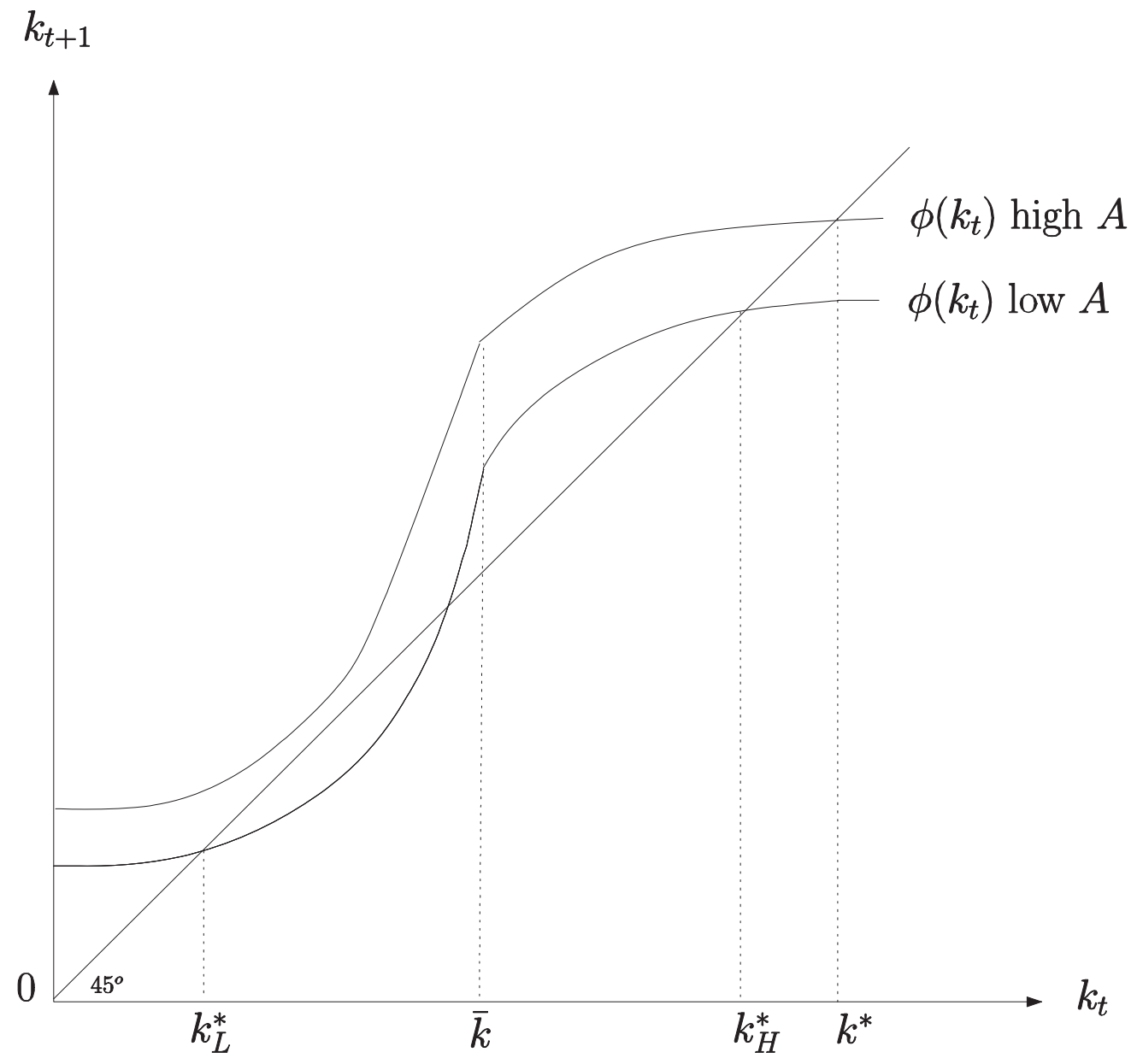

Figure 3. Evolution of capital per capita 


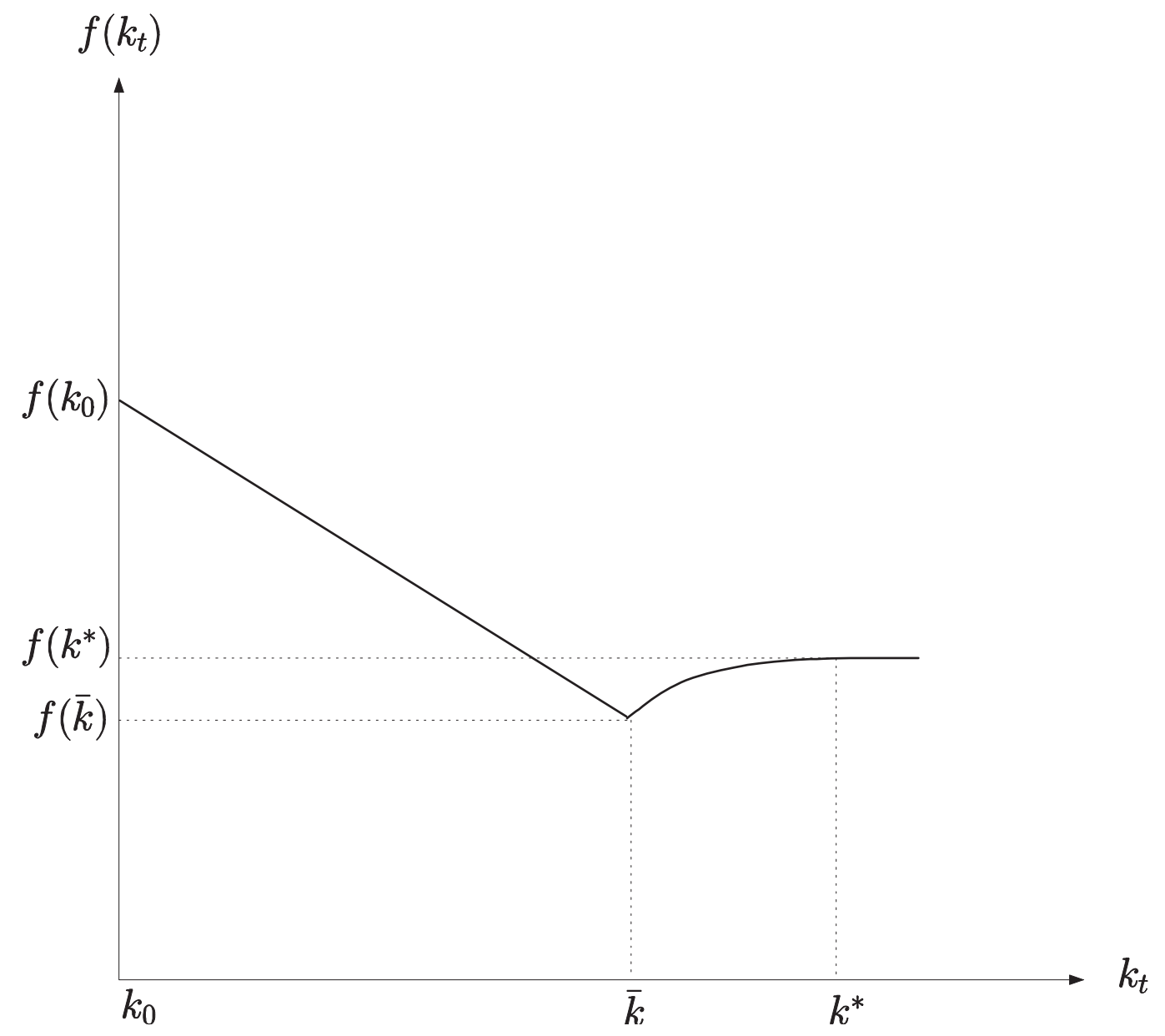

Figure 4. Evolution of Fertility 


\section{REFERENCES}

Apps, P. and R. Rees, "Fertility, Taxation and Family Policy," Scandinavian Journal of Economics, 106, 745-73, 2004.

Balestrino, A., A. Cigno and A. Pettini, "Endogenous Fertility and the Design of Family Taxation," International Tax and Public Finance, 9, 175-93, 2003.

Barro, R. and G. Becker, "A Reformulation of the Economic Theory of Fertility," The Quarterly Journal of Economics, CIII, 1 - 25, 1988.

Becker, G., K. Murphy and R. Tamura, "Human Capital, Fertility and Economic Growth," Journal of Political Economy, 98, 12-37, 1990.

Beenstock, M., "Do abler parents have fewer children?," Oxford Economic Papers, $59,430-57,2007$.

Cette, G., N. Dromel, and D. Meda, "Opportunity costs of having a child, financial constraints and fertility," Applied Economics Letters, 14, 239-44, 2007.

Chen, H., "Life Expectancy, fertility, and educational investment," Journal of Population Economics, 23, 37-56, 2010.

de la Croix, D. and M. Doepke, "Inequality and Growth: Why Differential Fertility Matters," American Economic Review, 93, 1091-113, 2003.

Galor, O. and D. Weil, "The Gender Gap, Fertility and Growth," The American Economic Review, 86, 374-87, 1996.

Goldstein, J., T. Sobotka and A. Jasilioniene, "The End of Lowest-Low Fertility," Population and Development Review, 35, 663 - 99, 2009.

Grimm, M, K. Harttgen, S. Klasen and M. Misselhorn, "A Human Development Index by Income Groups," World Development, 36, 2008.

Gronau, R. and D. Hamermesh, "Time vs. Goods: The Value of Measuring Household Production Technologies," Review of Income and Wealth, 52, 1-16, 2006.

Kimura, M. and D. Yasui, "Occupational Choice, Educational Attainment and Fertility," Economics Letters, 94, 228-234, 2007.

Luci, A. and O. Thevenon, "Does Economic Development Explain the Fertility Rebound in OECD countries?," Population and Societies, 481, 1-4, 2011.

Morrisson, C. and F. Murtin, "The Century of Education", Journal of Human Capital, 3, 1-42, 2009.

Myrskyla, M., H. Kohler and F. Billari, "Advances in development reverse fertility declines," Nature, 460, 741-743, 2009.

Rees, R. and R. Riezman, "Globalization, Gender and Growth," Review of Income and Wealth, 58, 107-17, 2012.

Rosenzweig, M, "Population Growth and Human Capital Investments: Theory and Evidence," Journal of Political Economy, 98, S38-S70, 1990.

Sato, Y., K. Tabata, K. and K. Yammamoto, "Technological Progress, Income Inequality and Fertility," Journal of Population Economics, 21, 135-57, 2008.

Thevenon, O., "Family Policies in OECD countries: A Comparative Analysis," Population and Development Review, 37, 57-87, 2011.

United Nations, "World Population Prospects: The 2010 Revision. Department of Economic and Social Affairs, Population Division, New York, 2011.

World Bank, World Bank Data Bank, http://data.worldbank.org/ World Bank, Washington D.C., The United States of America, 2012. 


\section{APPENDIX}

Equation of Motion (23)

Substituting the second line of (22) in (21) and noting that $w_{t}^{u}=A b$ yields

$k_{t+1}=\frac{(1-\gamma-\lambda)}{\gamma} A^{a} B\left[p_{x}(1-\beta)\right]^{1-a}\left[\frac{b+\left\{\frac{\theta^{1-\alpha}(1-\tau)^{1-\alpha}(1-\alpha)}{(1-a \gamma)^{\alpha}}-b \theta\right\} k_{t}}{b^{1-a}+\left\{\frac{\theta^{1-\alpha(1-a)}(1-\tau)^{1-\alpha(1-a)}(1-\alpha)^{1-a}}{(1-a \gamma)^{\alpha(1-a)}}-b^{1-a} \theta\right\} k_{t}}\right]$

Further substituting for $\theta^{-\alpha}$, using (19), and manipulating yields (23).

Proof of Proposition 2

Differentiating (23) and using (19) gives

$$
\phi^{\prime}\left(k_{t}\right)=A^{a} \tilde{B} \frac{(1-\gamma-\lambda)}{\gamma} \begin{cases}a \alpha\left[\frac{(1-\alpha)(1-\beta)}{(1-a \gamma)^{\alpha}(1-\tau)^{\alpha}}\right]^{a} k_{t}^{a \alpha-1}>0 & \text { if } k_{t} \geq \bar{k} \\ \frac{b^{a} \theta\left[(1-\tau)^{\frac{-a \gamma}{(1-a \gamma)}}-(1-\tau)^{\frac{a(1-\gamma)}{(1-a \gamma)}}\right]}{\left[1-\theta\left\{1-(1-\tau)^{\frac{a(1-\gamma)}{(1-a \gamma)}}\right\} k_{t}\right]^{2}}>0 \quad \text { if } k_{t}<\bar{k}\end{cases}
$$

Further differentiating, we obtain

$$
\phi^{\prime \prime}\left(k_{t}\right)=A^{a} \tilde{B} \frac{(1-\gamma-\lambda)}{\gamma}\left\{\begin{array}{cl}
-(1-a \alpha) a \alpha\left[\frac{(1-\alpha)(1-\beta)}{(1-a \gamma)^{\alpha}(1-\tau)^{\alpha}}\right]^{a} k_{t}^{a \alpha-2}<0 & \text { if } k_{t} \geq \bar{k} \\
\frac{b^{a} 2 \theta^{2}\left\{1-(1-\tau)^{\frac{a(1-\gamma)}{(1-\alpha)}}\right\}\left[(1-\tau)^{\frac{-a \gamma}{(1-a \gamma)}}-(1-\tau)^{\frac{a(1-\gamma)}{(1-a \gamma)}}\right]}{\left[1-\theta\left\{1-(1-\tau)^{\frac{a(1-\gamma)}{(1-\gamma)}}\right\} k_{t}\right]^{3}}>0 & \text { if } k_{t}<\bar{k}
\end{array}\right.
$$

Proof of Result 2

Differentiating (25a) gives

$$
\begin{array}{ll}
f^{\prime}\left(k_{t}\right)=-\frac{\gamma}{B}\left[\frac{A b}{p_{x}(1-\beta)}\right]^{1-a} \theta\left(1-(1-\tau)^{\frac{a(1-\gamma)}{(1-a \gamma)}}\right)<0 ; \quad f^{\prime \prime}\left(k_{t}\right)=0 & \text { if } k_{t}<\bar{k} \\
f^{\prime}\left(k_{t}\right)=\alpha(1-a) \frac{f\left(k_{t}\right)}{k_{t}}>0 ; \quad f^{\prime \prime}\left(k_{t}\right)=[\alpha(1-a)-1] \frac{f^{\prime}\left(k_{t}\right)}{k_{t}}<0 & \text { if } k_{t} \geq \bar{k}
\end{array}
$$

